\title{
Age related differences in work injuries and permanent impairment: a comparison of workers' compensation claims among adolescents, young adults, and adults
}

\author{
C Breslin, M Koehoorn, P Smith, M Manno
}

Occup Environ Med 2003;60:e 10(http://www.occenvmed.com/cgi/content/full/60/9/e10)

See end of article for authors' affiliations

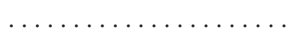

Correspondence to: Dr C Breslin, Institute for Work \& Health

481 University Ave.

Suite 800, Toronto, ON

M5G 2E9, Canada;

cbreslin@iwh.on.ca

Accepted

14 February 2003
Background: There is growing evidence that adolescent workers are at greater risk for work injury. Aims: To investigate the severity of work injuries across age groups.

Methods: Workers' compensation records were used to examine work related injuries among adolescents (15-19 years old), young adults (20-24 years old), and adults (25+ years old) between 1993 and 2000. The incidence of compensated injuries was calculated for each age group and compared by gender, industry, and type of injury. The presence and degree of permanent impairment in each age group was also examined.

Results: For males, adolescents and young adults had higher claim rates than adults. For females, adults had the highest claim rates and young adults the lowest. Rates of permanent impairment indicated that age was positively associated with severity of injury.

Conclusions: Indicators of health consequences, in particular presence of permanent impairment, provide preliminary evidence that compensated work injuries sustained by youth are not as serious as injuries sustained by adults. Nevertheless, there was evidence that some young workers sustain injuries that have long term consequences. Documenting the consequences of the injuries that young workers sustain has implications for secondary prevention efforts and health services policy.
$(2$ ver the past two decades, numerous studies of emergency department (ED) records, ${ }^{1-4}$ workers' compensation claims, ${ }^{5-11}$ and self report surveys ${ }^{12-19}$ have documented that adolescents are injured at work frequently enough to consider it a public health concern in the USA, Canada, and Europe. Not only do a substantial number of adolescents sustain work injuries, these injuries also occur more frequently compared to their adult counterparts. ${ }^{39} 171920$ For example, records from a representative sample of EDs in the USA showed that adolescent and young adult workers had the highest rates of work injuries per 100 full time equivalents. ${ }^{3}$ These age differences were particularly marked for males, with adolescent and young adult males' injury rates at 1.5-4 times the rates of males over 25 years. Burns and lacerations accounted for half of the injuries to young workers and approximately one fourth to one third of injuries to adult workers. These studies indicate that the likelihood of work injuries varies by age, and that the magnitude of these age related differences depends on gender and the type of injury examined.

Both general and youth specific factors have been posited to explain the increased work injury rates among adolescents and young adults. The degree and type of work hazard exposure can differ across age groups. Adolescents, and to a lesser extent young adults, are concentrated in the retail trade and service sector, ${ }^{21}{ }^{22}$ resulting in many acute injuries such as cuts, burns, and falls. ${ }^{14}$ Among 15-24 year olds, more than 50\% of all claims in that age group occurred in the first five months on the job, ${ }^{23}$ indicating that lack of experience may play a particularly important role for young workers. In addition, about half of adolescents and young adults report having received no safety training. ${ }^{212}{ }^{25}$ Maturational factors such as musculoskeletal and cognitive development are also thought to predispose adolescents to work injuries. ${ }^{26}{ }^{27}$ Although these developmental factors may help explain adolescents' increased claim rates, these factors are less plausible for explaining the increased risk among young adults.
Even though young workers may be injured more frequently than their adult counterparts, it is not clear whether the severity of the injuries is similar across age groups. One indicator of the severity of the work injury is whether it resulted in permanent impairment. Fifteen to $26 \%$ of adolescent workers surveyed report permanent impairments, with the most common impairments being chronic pain, scarring, sensory loss, and loss of range of motion. ${ }^{12}{ }^{13}$ The proportion of injured adolescent workers who are determined to have a permanent impairment varies markedly in workers' compensation claim data, from a low of $3.4 \%$ of injured adolescent in Texas to $40 \%$ in New York state. ${ }^{6}$ Comparisons across compensation systems are difficult because of differences in definitions of permanent impairment, how it was assessed, and the level of compensation associated with permanent impairment. Nevertheless, these studies suggest that some adolescents do experience permanent impairment for work injuries. However, whether permanent impairment occurs as often among adolescent and young adult workers as adult workers remains to be determined.

Using workers' compensation data, the primary goal of this study was to determine the incidence rates and severity of work related injuries among adolescents (15-19 years old), young adults (20-24 years old), and adults (25+ years old). Specifically we sought to examine the following research questions: (1) are gender differences in claim rates similar across different age groups; (2) are any age related differences in claim rates exhibited in both goods producing and service sectors; (3) are certain types of injuries more common among young workers than adult workers; and (4) is the presence and degree of permanent impairment comparable across age groups?

Abbreviations: ED, emergency department; LT, lost time; WMSD, work related musculoskeletal disorders 
Table 1 Number and rate of lost time claims by gender and age group, 1993-2000

\begin{tabular}{|c|c|c|c|c|}
\hline & Injuries & FTEs & Rate* & $95 \% \mathrm{Cl}$ \\
\hline \multicolumn{5}{|l|}{$15-19 y$} \\
\hline Females & 9926 & 491111 & 20.21 & 19.82 to 20.61 \\
\hline Males & 23145 & 588942 & 39.30 & 38.80 to 39.81 \\
\hline Missing gender information & 10 & & & \\
\hline \multicolumn{5}{|l|}{$20-24$ y } \\
\hline Females & 25379 & 1368524 & 18.54 & 18.32 to 18.77 \\
\hline Males & 72769 & 1684465 & 43.20 & 42.89 to 43.52 \\
\hline Missing gender information & 26 & & & \\
\hline \multicolumn{5}{|l|}{$25+y$} \\
\hline Females & 241946 & 11544509 & 20.96 & 20.87 to 21.04 \\
\hline Males & 533545 & 15413104 & 34.62 & 34.52 to 34.71 \\
\hline Missing gender information & 167 & & & \\
\hline
\end{tabular}

\section{METHODS}

For the years 1993 to 2000, accepted, short term injury claims (that is, less than one year) involving wage replacement for time loss were obtained for workers 15 years and older from the workers' compensation system in Ontario. In 1999, 68\% of Ontario workers were covered through the compensation system. ${ }^{28}$ Workers not covered included those self employed, domestic workers, federal government workers, the majority of the finance industry, and workers associated with interprovincial commerce (for example, railroads).

In Canada, minimum age restrictions on work are primarily regulated by each province. ${ }^{29}{ }^{30}$ In Ontario, for example, the regulations set 14 years old as the minimum age for employment in offices or stores, 15 for factory work, 16 for logging, and 18 for underground mining. Other Canadian jurisdictions such as British Columbia restrict paid employment for adolescents under 15, but only prohibit very hazardous jobs (for example, use of chemical toxins, explosives) between the ages of 15 and 17 years. Whether legally or illegally employed, workers under 18 years are entitled to wage replacement due to time loss if the injury occurred while working for a firm covered by the compensation system.

Each lost time (LT) claim included information on sociodemographics such as age and gender, industrial sector, the nature of the injury, and the presence and degree of permanent impairment. The industrial classification is based on the industry the claimant's firm operates in and is coded according to the 1980 Standard Industrial Classification codes at the four digit level. ${ }^{31}$ This classification system can be aggregated into two major industrial groups, the goods producing (for example, manufacturing) and service sectors (for example, food service).

The Canadian Work Injury Standard codes were used to classify the nature of the injury. ${ }^{32}$ For this study, sprains and strains were categorised separately from other work related musculoskeletal disorders (WMSD; for example, tendinitis, inflammation of joints).

Workers who suffer permanent impairment due to workplace injuries are entitled to permanent impairment benefits under the Workers' Compensation Act. ${ }^{33}$ Workers were eligible for these benefits if their impairment was unlikely to change substantially in the next year with or without treatment. The presence and degree of permanent impairment was determined by physicians and were based on formulae outlined in the Guides to the evaluation of permanent impairment, 4th edition. ${ }^{34}$ This evaluation system also provides specific guidelines for assessing the degree of impairment, ranging from $0 \%$ to $100 \%$ impairment. In the present study, presence of impairment was defined as $1 \%$ or more.

\section{Analytical strategy}

Incidence rates per 1000 full time equivalents (FTEs) for lost time claims were computed by age group. Estimates of the number of workers and work hours for each age group (that is, denominators) were derived from the Canadian Labour Force Survey. ${ }^{35}$ People working in the finance and federal government industries were excluded as it is likely they are not covered under the mandate of the Workplace Safety and Insurance Board. For each month between 1993 and 2000, the total hours worked was estimated for Ontario workers. The FTE estimates were then summed across the years 1993 to 2000 to give an FTE estimate across the time period of this study by age group, stratified by gender and industry.

Confidence intervals for the incidence rates were used to assess age related differences (for formula used to calculate confidence intervals, see the appendix).

\section{RESULTS}

Table 1 presents the claim rates by age and gender. These rates are based on work hours reported by each age/gender subgroup across the 1993-2000 time period. Across all age groups, the claim rate for males was approximately twice that for females. Among males, young adult males had the highest injury rates (43.2/1000 FTEs), followed by adolescent and adult males (39.3/1000 and 34.6/1000, respectively). Among females, adult females had the highest claim rate $(20.96 / 1000$ FTEs) and young adults the lowest (18.54/1000), with adolescent females falling in between (20.21/1000).

Table 2 compares the claim rates by age and industry. The claims rates for workers in the service industry, although statistically significant, were quite comparable across adolescents, young adults, and adults (27.86/1000 FTEs, 26.68/1000, $25.49 / 1000$, respectively). For adolescents, the largest proportion of claims in the service industries occurred within the sector that includes retail trade and accommodation, food, and beverage service $(79 \%)$. This service sector also accounted for the most injuries among young adults and adults $(63 \%$ and $33 \%$, respectively), but to a lesser degree than for adolescents. Rates in the goods industry were markedly higher for young adults (47.15/1000 FTEs) and adolescents (41.80/1000) than for adults $(35.32 / 1000)$. For adolescents, the largest proportion of claims in the goods producing industries occurred within the manufacturing sectors $(55 \%)$. This was also the case among young adults and adults (53\% and 49\%, respectively).

Table 3 shows claim rates by age, gender, and nature of injury. Within each age/gender group, sprains and strains represented the highest proportion of claims. However, the rate of sprains and strains for adolescents (males $=10.56 / 1000$ FTEs; females $=5.85 / 1000$ ) was significantly lower compared to adults (males $=15.75 / 1000$ FTEs; females $=10.26 / 1000$ ). Although young adult females (7.97/1000 FTEs) also showed a lower rate of sprains and strains than adult females, young adult males (16.10/1000) showed a slightly higher rate than adult males. Rates of cuts were significantly higher among 
Table 2 Number and rate of lost time claims by industry and age group, 1993-2000

\begin{tabular}{|c|c|c|c|c|}
\hline & Injuries & FTEs & Rate* & $95 \% \mathrm{Cl}$ \\
\hline \multicolumn{5}{|l|}{$15-19 y$} \\
\hline Goods & 8945 & 214020 & 41.80 & 40.94 to 42.67 \\
\hline Services & 24132 & 866033 & 27.86 & 27.52 to 28.22 \\
\hline Missing industry classification & 4 & & & \\
\hline \multicolumn{5}{|l|}{$20-24$ y } \\
\hline Goods & 38478 & 816032 & 47.15 & 46.68 to 47.63 \\
\hline Services & 59689 & 2236956 & 26.68 & 26.47 to 26.90 \\
\hline Missing industry classification & 7 & & & \\
\hline \multicolumn{5}{|l|}{$25+$ years } \\
\hline Goods & 316126 & 8949837 & 35.32 & 35.20 to 35.45 \\
\hline Services & 458955 & 18007776 & 25.49 & 25.41 to 25.56 \\
\hline Missing industry classification & 577 & & & \\
\hline \multicolumn{5}{|c|}{$\begin{array}{l}\text { Industries classified as goods producing from the workers' compensation system include agriculture, } \\
\text { automotive, chemical processing, contstruction, forestry, manufacturing, mining, pulp \& paper, and steel. } \\
\text { Industries classified as goods producing in the Labour Force Survey include agriculture, other primary } \\
\text { industries, manufacturing, and construction. } \\
\text { Industries classified as service from the workers' compensation system include education, electrical utilities, } \\
\text { food, health care, municipal, services, transportation, and schedule } 2 \text {. Industries classified as service from the } \\
\text { Labour Force Survey include transport/communication/utilities, wholesale trade, retail trade, finance, } \\
\text { insurance, community services, personal services, business \& misc services, and public administration. } \\
\text { * Rate per } 1000 \text { FTEs. }\end{array}$} \\
\hline
\end{tabular}

adolescents $($ males $=8.77 / 1000$ FTEs; females $=3.61 / 1000$ ) and young adults (males $=6.50 / 1000$ FTEs; females $=$ $1.77 / 1000$ ) than adults (males $=3.00 / 1000$ FTEs; females $=$ $1.09 / 1000)$.

Table 4 shows the rate of permanent impariments by age group. Overall, adolescents (0.59/1000 FTEs) had a lower rate of permanent impairment compared to young adults (1.02/ $1000)$ and adults $(2.54 / 1000)$. This age related trend held for all but three types of injuries (amputations, burns, and cuts). Most notably, adolescents (0.17/1000 FTEs) showed a significantly higher rate of permanent impairment for amputations than adults $(0.11 / 1000)$. To better understand why all amputations were not assessed as resulting in permanent impairment, we broke down the claims for amputations by part of the body. Across all age groups, 95\% of amputations involved the finger or finger tip. Thus, some of these types of amputations appeared to have been judged to not have impaired functioning.

Within each age group, the type of injury with the highest rate of permanent impairment differed. For adolescents, amputations had the highest rate of permanent impairment (0.17/1000 FTEs), while sprains and strains led to the highest rate of permanent impairment for the other age groups (young adults, 0.27/1000; adults, 1.03/1000).

Among those with permanent impairment, we also calculated the mean percentage impairment rating by age group, another indicator of the level of injury severity. Adolescents showed the lowest impairment rating (mean $=11.64, \mathrm{CI}$ $95 \% 10.71$ to 12.58 ), and this mean rating was not significantly different from the mean rating for young adults $($ mean $=12.91$, CI 95\% 12.53 to 13.29). However, adults had a significantly higher mean impairment rating (mean $=15.48$, CI $95 \% 15.38$ to 15.57 ) than adolescents or young adults.

\section{DISCUSSION}

Using workers' compensation data, the present study examined age and gender patterns in work related injuries. An important feature of this study was an examination of age related differences in permanent impairment among injured workers. Consistent with previous research, male adolescents and young adults showed higher claim rates than their adult male counterparts. Also as expected, females exhibited claim rates that were one half to two thirds that of males. However, females showed a different pattern with regard to age, with adult and adolescent females having generally comparable claim rates and young adult females showing lower rates. Comparisons of rates of certain types of injuries provide a preliminary indication of how this pattern occurred. For young adult females, their risk for cuts was half that of adolescent females. Young adult females also had a lower rate of sprains and strains compared to adult females. Young adults therefore appeared to move out of the risk period for prototypically adolescent injuries, but had not fully entered the period of risk for injuries more common among adult females, sprains and strains. A bettering understanding of the developmental and environmental factors that lead to these age and gender differences would be helpful in targeting injury prevention interventions.

As with previous studies, variation in claim rates by industry and by type of injury suggest that work related risk factors such as hazard exposure contribute to young worker's increased risk. However, the notion that cognitive and physical development play a major role in injury risk is not strongly supported by our findings. In particular, young adult males had the highest injury rate, an age group where maturational factors would be less plausible for explaining injuries. Even though maturational factors may be relevant, these findings for males may indicate that a different combination of general risk factors (for example, work hazards) and unique risk factors (for example, stage of maturation) may operate across adolescence and young adulthood.

Across age groups, musculoskeletal conditions (that is, strains and sprains) were an important part of the work injury picture in this study. Sprains and strains were the leading cause of injury for all age groups, though they constituted a smaller proportion of adolescent claims. Nevertheless, musculoskeletal disorders, especially back injuries, may increase young workers' vulnerability to further injuries. Evidence from several studies indicates that a history of back problems is a predictor of future back injuries and delayed recovery. ${ }^{36-40}$ Musculoskeletal conditions also appeared to be the primary contributor to the progressive increase across age groups in rates of permanent impairment. Indeed, the adult rate of permanent impairment for sprains and strains alone was higher than the adolescent rates of permanent impairment for all types of injuries combined. These marked differences with respect to chronic conditions such as musculoskeletal disorders might be partially explained by the fact that adolescents have not only had less time for musculoskeletal disorders to arise, but also have had less time to show a history of impaired work functioning due to such a condition, an 
Table 3 Number and rate of lost time claims by nature of injury and age group, 1993-2000

\begin{tabular}{|c|c|c|c|}
\hline & Injuries & Rate* & $95 \% \mathrm{Cl}$ \\
\hline \multicolumn{4}{|l|}{ Males, $15-19$ y } \\
\hline Amputations & 336 & 0.57 & 0.51 to 0.63 \\
\hline Burns & 1221 & 2.07 & 1.96 to 2.19 \\
\hline Contusions & 3487 & 5.92 & 5.73 to 6.12 \\
\hline Cuts & 5163 & 8.77 & 8.53 to 9.01 \\
\hline Fractures & 1373 & 2.33 & 2.21 to 2.46 \\
\hline Other & 2898 & 4.92 & 4.74 to 5.10 \\
\hline Sprains and strains & 6221 & 10.56 & 10.30 to 10.83 \\
\hline WMSD & 2416 & 4.10 & 3.94 to 4.27 \\
\hline Total & 23115 & 39.25 & 38.75 to 39.76 \\
\hline Missing nature of injury classification & 30 & & \\
\hline \multicolumn{4}{|l|}{ Females, $15-19$ y } \\
\hline Amputations & 75 & 0.15 & 0.12 to 0.19 \\
\hline Burns & 1098 & 2.24 & 2.11 to 2.37 \\
\hline Contusions & 1482 & 3.02 & 2.87 to 3.18 \\
\hline Cuts & 1772 & 3.61 & 3.44 to 3.78 \\
\hline Fractures & 350 & 0.71 & 0.64 to 0.79 \\
\hline Other & 1130 & 2.30 & 2.17 to 2.44 \\
\hline Sprains and strains & 2874 & 5.85 & 5.64 to 6.07 \\
\hline WMSD & 1141 & 2.32 & 2.19 to 2.46 \\
\hline Total & 9922 & 20.20 & 19.81 to 20.60 \\
\hline Missing nature of injury classification & 4 & & \\
\hline \multicolumn{4}{|l|}{ Males, $20-24$ y } \\
\hline Amputations & 640 & 0.38 & 0.35 to 0.41 \\
\hline Burns & 1792 & 1.06 & 1.02 to 1.11 \\
\hline Contusions & 10490 & 6.23 & 6.11 to 6.35 \\
\hline Cuts & 10955 & 6.50 & 6.38 to 6.63 \\
\hline Fractures & 4240 & 2.52 & 2.44 to 2.59 \\
\hline Other & 9802 & 5.82 & 5.70 to 5.94 \\
\hline Sprains and strains & 27112 & 16.10 & 15.90 to 16.29 \\
\hline WMSD† & 7623 & 4.53 & 4.43 to 4.63 \\
\hline Total & 72654 & 43.13 & 42.82 to 43.45 \\
\hline Missing nature of injury classification & 115 & & \\
\hline \multicolumn{4}{|l|}{ Females, $20-24$ y } \\
\hline Amputations & 111 & 0.08 & 0.07 to 0.10 \\
\hline Burns & 1102 & 0.81 & 0.76 to 0.85 \\
\hline Contusions & 3652 & 2.67 & 2.58 to 2.76 \\
\hline Cuts & 2424 & 1.77 & 1.70 to 1.84 \\
\hline Fractures & 819 & 0.60 & 0.56 to 0.64 \\
\hline Other & 3265 & 2.39 & 2.31 to 2.47 \\
\hline Sprains and strains & 10913 & 7.97 & 7.83 to 8.13 \\
\hline WMSD & 3051 & 2.23 & 2.15 to 2.31 \\
\hline Total & 25337 & 18.51 & 18.29 to 18.74 \\
\hline Missing nature of injury classification & 42 & & \\
\hline \multicolumn{4}{|l|}{ Males, $25+y$} \\
\hline Amputations & 4138 & 0.27 & 0.26 to 0.28 \\
\hline Burns & 6443 & 0.42 & 0.41 to 0.43 \\
\hline Contusions & 60880 & 3.95 & 3.92 to 3.98 \\
\hline Cuts & 46274 & 3.00 & 2.98 to 3.03 \\
\hline Fractures & 36624 & 2.38 & 2.35 to 2.40 \\
\hline Other & 71345 & 4.63 & 4.60 to 4.66 \\
\hline Sprains and strains & 242726 & 15.75 & 15.69 to 15.81 \\
\hline WMSD & 63354 & 4.11 & 4.08 to 4.14 \\
\hline Total & 531784 & 34.50 & 34.41 to 34.59 \\
\hline Missing nature of injury classification & 1906 & & \\
\hline \multicolumn{4}{|l|}{ Females, $25+y$} \\
\hline Amputations & 634 & 0.05 & 0.05 to 0.06 \\
\hline Burns & 3267 & 0.28 & 0.27 to 0.29 \\
\hline Contusions & 30860 & 2.67 & 2.64 to 2.70 \\
\hline Cuts & 12558 & 1.09 & 1.07 to 1.11 \\
\hline Fractures & 11448 & 0.99 & 0.97 to 1.01 \\
\hline Other & 30467 & 2.64 & 2.61 to 2.67 \\
\hline Sprains and strains & 118405 & 10.26 & 10.20 to 10.31 \\
\hline WMSD† & 33650 & 2.91 & 2.88 to 2.95 \\
\hline Total & 241289 & 20.90 & 20.82 to 20.98 \\
\hline Missing nature of injury classification & 703 & & \\
\hline
\end{tabular}

essential part of the assessment to determine permanent impairment. Given the age related pattern we have observed in this study, it appears that programmes designed to prevent or minimise the impact of musculoskeletal disorders should be implemented in adolescence or young adulthood, before these conditions become the prominent part of the adult lost time claim and permanent impairment picture.

Certain limitations associated with this administrative data should be noted. Workers who are self employed or who work in small family businesses may not be well represented in the 


\begin{tabular}{|c|c|c|c|}
\hline & Injuries & Rate* & $95 \% \mathrm{Cl}$ \\
\hline \multicolumn{4}{|l|}{$15-19$ y } \\
\hline Amputations & 181 & 0.17 & 0.14 to 0.19 \\
\hline Burns & 13 & 0.01 & 0.01 to 0.02 \\
\hline Contusions & 21 & 0.02 & 0.01 to 0.03 \\
\hline Cuts & 120 & 0.11 & 0.09 to 0.13 \\
\hline Fractures & 132 & 0.12 & 0.10 to 0.14 \\
\hline Other & 75 & 0.07 & 0.06 to 0.09 \\
\hline Sprains and strains & 72 & 0.07 & 0.05 to 0.08 \\
\hline WMSD $†$ & 28 & 0.03 & 0.02 to 0.04 \\
\hline Total & 642 & 0.59 & 0.55 to 0.64 \\
\hline $\begin{array}{l}\text { Missing permanent } \\
\text { impairment status }\end{array}$ & 5 & & \\
\hline \multicolumn{4}{|l|}{$20-24$ y } \\
\hline Amputations & 396 & 0.13 & 0.12 to 0.14 \\
\hline Burns & 32 & 0.01 & 0.01 to 0.01 \\
\hline Contusions & 176 & 0.06 & 0.05 to 0.07 \\
\hline Cuts & 398 & 0.13 & 0.12 to 0.14 \\
\hline Fractures & 550 & 0.18 & 0.17 to 0.20 \\
\hline Other & 442 & 0.14 & 0.13 to 0.16 \\
\hline Sprains and strains & 822 & 0.27 & 0.25 to 0.29 \\
\hline WMSD $†$ & 296 & 0.10 & 0.09 to 0.11 \\
\hline Total & 3112 & 1.02 & 0.98 to 1.06 \\
\hline $\begin{array}{l}\text { Missing permanent } \\
\text { impairment status }\end{array}$ & 25 & & \\
\hline \multicolumn{4}{|l|}{$25+y$} \\
\hline Amputations & 3012 & 0.11 & 0.11 to 0.12 \\
\hline Burns & 370 & 0.01 & 0.01 to 0.02 \\
\hline Contusions & 3915 & 0.15 & 0.14 to 0.15 \\
\hline Cuts & 3541 & 0.13 & 0.13 to 0.14 \\
\hline Fractures & 8807 & 0.33 & 0.32 to 0.33 \\
\hline Other & 10077 & 0.37 & 0.37 to 0.38 \\
\hline Sprains and strains & 27858 & 1.03 & 1.02 to 1.05 \\
\hline WMSDT & 10929 & 0.41 & 0.40 to 0.41 \\
\hline Total & 68509 & 2.54 & 2.52 to 2.56 \\
\hline $\begin{array}{l}\text { Missing permanent } \\
\text { impairment status }\end{array}$ & 411 & & \\
\hline
\end{tabular}

lost time claim figures. Even in work settings covered by workers' compensation, underreporting of work injuries is one issue that may be particularly relevant to youth. ${ }^{13}$ Consequently, the conclusions based on these data should be viewed as tentative, but justified in light of the limited number of previous studies examining age related differences in work injuries and their long term consequences.

The present findings provide preliminary support for policy recommendations regarding primary and secondary prevention. Given the limitations of workers' compensation data, relevant federal and provincial agencies should develop a comprehensive plan for monitoring work related injuries and for monitoring biochemical, physical, and psychosocial hazards to which workers are exposed. In particular, additional resources could be allocated to monitor injuries of individuals just starting a job or entering the labour force. Effective and comprehensive health and safety training for adolescents and young adults has rarely been evaluated (for an exception, see Banco and colleagues ${ }^{41}$ ). Consequently, federal and provincial ministries of labour and education should determine the effectiveness and coverage of current school based and work based safety training initiatives. In terms of secondary prevention, health care services could be targeted to reduce the duration and severity of the disability associated with a work injury. Permanent impairment among adolescents and young adults, though less frequent than for adults, is of concern because these long term health consequences may result in increased need of health care services into adulthood. In addition people with permanent disabilities show reduced earning capacity and increased risk of poverty ${ }^{42}$ Medical and behavioural intervention provided early in the disability process may enhance the functional capacity of the injured worker.

\section{APPENDIX: ESTIMATION OF RATE PARAMETER AND CORRESPONDING VARIANCE}

Assume we observe iid count data $x_{1}, x_{2}, \ldots, x_{n}$ with corresponding follow up or exposure times $t_{1}, t_{2}, \ldots, t_{n}$. We assume each count comes from a Poisson distribution with frequency function:

$$
P\left(X_{i}=x\right)=\frac{\exp \left(-\lambda t_{i}\right)\left(\lambda t_{i}\right)^{x}}{x !}, \quad i=1, \ldots, n
$$

Hence, each count has mean and variance $\lambda t$.

We are interested in estimating the rate parameter $\lambda$ and its corresponding variance. The likelihood is given by:

$$
L=\prod_{i=1}^{n} \frac{\exp \left(-\lambda t_{i}\right)\left(\lambda t_{i}\right)^{x_{i}}}{x_{i} !}
$$

Taking logarithms and disregarding terms that don't involve $\lambda$, we get:

$$
\log L=-\lambda \sum_{i=1}^{n} t_{i}+\left(\sum_{i=1}^{n} x_{i}\right) \log \lambda .
$$

Differentiating with respect to $\lambda$ gives:

$$
\frac{d \log L}{d \lambda}=-\sum_{i=1}^{n} t_{i}+\frac{1}{\lambda} \sum_{i=1}^{n} x_{i} .
$$

Setting the expression to zero and solving for $\lambda$ gives the following estimator:

$$
\hat{\lambda}=\frac{\sum_{i=1}^{n} x_{i}}{\sum_{i=1}^{n} t_{i}}
$$

An estimate for the variance can be obtained using the relation:

$$
\hat{\lambda}=\frac{\sum_{i=1}^{n} x_{i}}{\sum_{i=1}^{n} t_{i}} .
$$

where the expectation is taken with respect to the $x_{i}^{\prime}$ s. Application of the above formula gives:

$$
\operatorname{Var}(\hat{\lambda})=\frac{\lambda}{\sum_{i=1}^{n} t_{i}}
$$

Since we don't know the value of $\lambda$, so we replace it in the above expression with its estimate $\hat{\lambda}$. A 95\% confidence interval for $\lambda$ can then be constructed based on the above estimate and variance formula, i.e. 


$$
\hat{\lambda} \pm 1.96 \sqrt{\frac{\hat{\lambda}}{\sum_{i=1}^{n} t_{i}}} .
$$

However, because the sampling distribution of $\hat{\lambda}$ tends to be skewed and non-normal, this formula is not the best choice for constructing a confidence interval. Another undesirable property of the above formula is the potential to get a lower confidence bound which is negative. An improved confidence interval can be obtained by considering the log transformation of $\hat{\lambda}$. An application of the delta method (see Agresti ${ }^{43}$ for example) yields, after some simplification, the following variance estimate for $\log \hat{\lambda}$ :

$$
\begin{aligned}
V \hat{a} r(\log \hat{\lambda}) & =\frac{1}{\hat{\lambda} \sum_{i=1}^{n} t_{i}} . \\
& =\frac{1}{\sum_{i=1}^{n} x_{i}}
\end{aligned}
$$

A $95 \%$ confidence interval for $\lambda$ is then given by:

$$
\exp \left\{\log \hat{\lambda} \pm 1.96 \frac{1}{\sqrt{\sum x_{i}}}\right\}
$$

\section{Authors' affiliations}

C Breslin, M Koehoorn, P Smith, M Manno, Institute for Work \& Health, Toronto, Ontario

\section{REFERENCES}

1 Brooks DR, Davis LK, Gallagher SS. Work-related injuries among Massachusetts children: a study based on emergency department data. Am J Ind Med 1993;24:313-24.

2 Layne LA, Castillo DN, Stout N, et al. Adolescent occupational injuries requiring hospital emergency department treatment: a nationally representative sample. Am J Public Health 1994;84:657-60.

3 Centers for Disease Control and Prevention. Nonfatal occupational injuries and illnesses treated in hospital emergency departments-United States, 1998. Mor Mortal Wkly Rep 2001;50:313-17.

4 Hendricks KJ, Layne LA. Adolescent occupational injuries in fast food restaurants: an examination of the problem from a national perspective. J Occup Health Psychol 1999;41:1146-53

5 Banco L, Lapidus G, Braddock M. Work-related injury among Connecticut minors. Pediatrics 1992;89(5 pt 1):957-60.

6 Belville R, Pollack SH, Godbold J, et al. Occupational injuries among working adolescents in New York State. JAMA 1993;269:2754-9.

7 Brooks DR, Davis LK. Work-related injuries to Massachusetts teens, 1987-1990. Am J Ind Med 1996;29:153-60.

8 Cooper SP, Burau KD, Robison TB, et al. Adolescent occupational injuries: Texas, 1990-1996. Am J Ind Med 1999;35:43-50.

9 Miller ME, Kaufman JD. Occupational injuries among adolescents in Washington State, 1988-1991. Am J Ind Med 1998;34:121-32.

10 Schober SE, Handke JL, Halperin WE, et al. Work-related injuries in minors. Am J Ind Med 1988;14:585-95.

11 Heyer NJ, Franklin G, Rivara FP, et al. Occupational injuries among minors doing farm work in Washington State: 1986 to 1989. Am J Public Health 1992;82:557-60.

12 Parker DL, Carl WR, French LR, et al. Characteristics of adolescent work injuries reported to the Minnesota Department of Labor and Industry. Am $J$ Public Health 1994:84:606-11.

13 Parker DL, Carl WR, French LR, et al. Nature and incidence of self-reported adolescent work injury in Minnesota. Am J Ind Med 1994;26:529-41.
14 Dunn KA Runyan CW, Cohen LR, et al. Teens at work: a statewide study of jobs, hazards, and injuries. J Adolesc Health 1998;22:19-25.

15 Frone MR. Predictors of work injuries among employed adolescents. J Appl Psychol 1998;83:565-76.

16 Evensen CT, Schulman MD, Runyan CW, et al. The downside of adolescent employment: hazards and injuries among working teens in North Carolina. J Adolesc 2000;23:545-60.

17 Millar WJ. Accidents in Canada, 1988 and 1993. Health Reports 1995;7(2):7-16.

18 Hobbs S, McKechnie J. Child employment in Britian: a social and psychological analysis. Scotland: The Stationery Office, 1997.

19 Dupre D. Accidents at work in the EU 1998-1999. Statistics in Focus KS-NK-01-016-EN-I. Eurostat., 2001:1-7.

20 Rossignol AM, Locke JA, Burke JF. Employment status and the frequency and causes of burn injuries in New England. J Occup Med 1989:31:751-7.

21 National Research Council. Protecting youth at work: health, safety, and development of working children and adolescents in the United States. Washington, DC: National Academy Press, 1998.

22 Statistics Canada. Youths and the labour market. Ottawa: Statistics Canada, 1999.

23 Hertzman C, McGrail K, Hirtle B. Overall pattern of health care and social welfare use by injured workers in the British Columbia cohort. Int $J$ Law Psychiatry 1999;22:581-601.

24 Knight EB, Castillo DN, Layne LA. A detailed analysis of work-related injury among youth treated in emergency departments. Am J Ind Med 1995:27:793-805.

25 Industrial Accident Prevention Association. Canadian young workers workplace health and safety experience. Toronto, ON: Industria Accident Prevention Association, 2000.

26 Nelson MA. Sports medicine. In: Friedman SB, Fisher M, Schonberg SK, eds. Comprehensive adolescent health care. St Louis, MO: Quality Medical Publishers, Inc., 1992:1132-51.

27 Keating D. Adolescent thinking. In: Feldman S, Elliot G, eds. At the threshold: the developing adolescent. Cambridge, MA: Harvard University Press, 1990:54-89.

28 Sullivan T, Sinclair S. Health, safety and injuries in Canada. Presentation at the Melbourne Invitational Seminar, Syndey Australia, March 2001

29 Ministry of Labour. Employment Standards Act. http:// www.qp.gov.bc.ca/statreg/stat/E/96113 01.htm. Vancouver, British Columbia: Ministry of Labour, 1996.

30 Ontario Ministry of Labour. Information for working students: know your rights and obligations. http://www.gov.on.ca/lab/stu/facte.htm. Ministry of Labour, 2002.

31 Statistics Canada. Standard industrial classification, 1980. Ottawa: Statistics Canada, 1980.

32 Statistics Canada. Canadian work injuries standard. Ottawa, Statistics Canada, 1989

33 Workplace Safety and Insurance Board of Ontario. Workplace Safety and Insurance Board. Statistical supplement to the 1999 annual report. Workplace Safety an Insurance Board of Ontario, 2000: 1-32.

34 American Medical Association. Guides to the evaluation of permanent impairment, 4th edn. Chicago: American Medical Association, 1995.

35 Statistics Canada. Guide to the labour force survey. Ottawa: Statistics Canada, 2000.

36 Krause N, Frank JW, Dasinger LK, et al. Determinants of duration of disability and return-to-work after work-related injury and illness: challenges for future research. Am J Ind Med 2001;40:464-84

37 Cheadle A, Franklin G, Wolfhagen $C$, et al. Factors influencing the duration of work-related disability: a population-based study of Washington State workers' compensation. Am J Public Health 1994;84:190-6.

38 Dasinger LK, Krause N, Deegan L, et al. Physical workplace factors and return to work after compensated low back injury: a disability phase-specific analysis. J Occup Environ Med 2000;42:323-33.

39 Mitchell LV, Lawler FH, Bowen D, et al. Effectiveness and cost-effectiveness of employer-issued back belts in areas of high risk for back injury. J Occup Med 1994;36:90-4.

40 Venning PJ, Walter SD, Stitt LW. Personal and job-related factors as determinants of incidence of back injuries among nursing personnel. $J$ Occup Med 1987;29:820-5.

41 Banco L, Lapidus G, Monopoli J, et al. The Safe Teen Work Project: a study to reduce cutting injuries among young and inexperienced workers. Am J Ind Med 1997;31:619-22.

42 Burke T. Lawyers, lawsuits and legal rights. Berkeley, CA: University of California Press, 2002

43 Agresti A. Categorical data analysis. New York: John Wiley \& Sons, 1990. 